\title{
CMTM6 promotes migration, invasion, and EMT by interacting with and stabilizing vimentin in hepatocellular carcinoma cells
}

Xiaoting Huang ${ }^{1,2+}$, Leyang Xiang ${ }^{3 \dagger}$, Baiyao Wang ${ }^{1,2}$, Jijie Hu ${ }^{5}$, Chunshan Liu ${ }^{1,2}$, Anbang Ren ${ }^{1,2}$, Kunpeng Du ${ }^{1,2}$, Gengtai Ye ${ }^{4}$, Yingying Liang ${ }^{1,2}$, Yunqiang Tang ${ }^{3^{*}}$, Dinghua Yang ${ }^{4^{*}}$ and Yawei Yuan ${ }^{1,2^{*}}$

\begin{abstract}
Background: CKLF like MARVEL transmembrane domain containing 6 (CMTM6) has been associated with the development in many kinds of cancers. However, the roles of CMTM6 in hepatocellular carcinoma (HCC) are largely unknown. Thus, the present study aimed to investigate the function of CMTM6 in HCC.

Methods: We analysed CMTM6 levels and functions using human HCC cell lines, paired HCC and adjacent nontumorous tissues, and a tissue microarray. CMTM6 expression was silenced using short hairpin RNAs and its was overexpressed from a lentivirus vector. CMTM6 mRNA and protein levels were determined using quantitative real-time reverse transcription PCR and western blotting, respectively. Proliferation, colony formation, migration, and invasion were assessed using a Cell counting kit-8, colony formation, wound-healing, and Matrigel invasion assays, respectively. Immunohistochemistry was used to score the expression of CMTM6 in tissue samples. The localization and binding partners of CMTM6 were investigated using immunofluorescence and coimmunoprecipitation experiments, respectively. A mouse xenograft model was used for in vivo studies.

Results: Compared with that in adjacent, non-cancerous tissue, Here, CMTM6 levels were increased in HCC tissue samples. Silencing of CMTM6 suppressed the proliferation, migration, and invasion of HCC cells. Conversely, CMTM6 overexpression enhanced HCC cell invasion, migration, and proliferation. Mechanistically, CMTM6 physically interacts with and stabilizes vimentin, thus inducing epithelial-mesenchymal transition (EMT), which promotes proliferation, migration and invasion. Importantly, in HCC tissues, CMTM6 expression correlated positively with vimentin levels. Poor prognosis of HCC was associated significantly with higher CMTM6 expression.
\end{abstract}

\footnotetext{
*Correspondence: gyzl_tang@126.com; dhyangyd@yahoo.com; nfyangdh@163.com; yuanyawei@gzhmu.edu.cn

${ }^{+}$Xiaoting Huang and Leyang Xiang contributed equally to this work

1 Department of Radiation Oncology, Affiliated Cancer Hospital \&

Institute of Guangzhou Medical University, No. 78 Hengzhigang Road,

Guangzhou 510095, Guangdong, People's Republic of China

${ }^{3}$ Department of Surgery, Affiliated Cancer Hospital \& Institute

of Guangzhou Medical University, No. 78 Hengzhigang Road,

Guangzhou 510095, Guangdong, People's Republic of China

${ }^{4}$ Unit of Hepatobiliary Surgery, Department of General Surgery, Nanfang

Hospital, Southern Medical University, 1838 North Guangzhou Avenue,

Baiyun District, Guangzhou 510515, China

Full list of author information is available at the end of the article
}

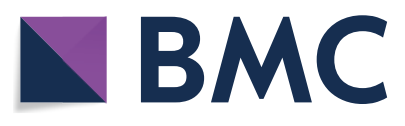

(c) The Author(s) 2021. This article is licensed under a Creative Commons Attribution 4.0 International License, which permits use, sharing, adaptation, distribution and reproduction in any medium or format, as long as you give appropriate credit to the original author(s) and the source, provide a link to the Creative Commons licence, and indicate if changes were made. The images or other third party material in this article are included in the article's Creative Commons licence, unless indicated otherwise in a credit line to the material. If material is not included in the article's Creative Commons licence and your intended use is not permitted by statutory regulation or exceeds the permitted use, you will need to obtain permission directly from the copyright holder. To view a copy of this licence, visit http://creativeco mmons.org/licenses/by/4.0/. The Creative Commons Public Domain Dedication waiver (http://creativecommons.org/publicdomain/ zero/1.0/) applies to the data made available in this article, unless otherwise stated in a credit line to the data. 
Conclusions: CMTM6 has an important function in HCC proliferation, migration, and invasion, via its interaction with and stabilization of vimentin. CMTM6 might represent a potential biomarker and therapeutic target to treat HCC.

Keywords: HCC, CMTM6, EMT, Proliferation, Migration, Invasion

\section{Background}

Hepatocellular carcinoma (HCC), a major type of liver cancer, is one of the most common malignancies worldwide and is associated with high mortality [1]. HCC is also one of the most common cancers in China, in which 230,000 patients with HCC die each year [2]. Although there have been continuous improvements in medical technology for HCC treatment, the 5-year survival rate of $\mathrm{HCC}$ is $<30 \%$, primarily because of early metastasis, representing the major obstacle for $\mathrm{HCC}$ treatment [3, 4]. Therefore, is critical to identify the molecular mechanisms involved HCC metastasis.

CKLF like MARVEL transmembrane domain containing 6 (CMTM6) is expressed at the plasma membrane of various cancer cells [5-7]. Recent studies indicated that CMTM6 is an important regulator of programmed cell death 1 ligand 1 (PD-L1); CMTM6 interacts with PD-L1 and prevents its lysosomal degradation, thus stabilising PD-L1 in the membrane [8]. Inhibition of CMTM6 led to decreased PD-L1 protein levels and enhanced tumourspecific T-cell activity [9]. Several studies indicated that CMTM6 expression correlated positively with PD-L1 expression and was associated with poor prognosis of various cancers [7]. Moreover, in neck squamous cell carcinoma cells, CMTM6 is involved in the maintenance of cancer stem cell (CSC) phenotypes and the induction of epithelial-mesenchymal transition (EMT) by transforming growth factor beta (TGF $\beta$ ), associated with enhanced Wnt/b-catenin signalling $[6,10]$. These findings suggest CMTM6 as a promising target molecule in cancer treatment. However, in HCC, the function of CMTM6 largely unknown.

EMT is a cellular process by which epithelial cells gain a mesenchymal phenotype through specific changes in gene expression [6]. EMT-induced changes in epithelial plasticity are evidenced by the loss of epithelial markers, such as E-cadherin, and increased expression of mesenchymal proteins, such as N-cadherin and Vimentin, and the EMT transcription factors such as snail family transcriptional repressor 1 (SNAI1) and Twist family BHLH transcription factor 1 (Twist) [11]. During EMT, there is a restructuring of the epithelial cytoskeleton, resulting in loss of connections with the basement membrane and cell polarity, leading to increased cellular metastatic abilities [12]. Emerging evidence indicated that in certain cancer, such as HCC, EMT participates in metastasis and recurrence [13]. Some studies indicated that HCC cells acquire a more invasive and aggressive CSC phenotype through EMT [14]. Moreover, EMT also implicated in chemoresistance of HCC cells and plays a key role in therapeutic responsiveness of HCC [15]. Therefore, to treat HCC, a promising strategy might be inhibiting metastasis and increasing chemosensitivity by regulating EMT.

The present study aimed to assess the role of CMTM6 in HCC. The results demonstrated upregulation of CMTM6 in HCC tissue samples compared with that in adjacent normal tissues. CMTM6 promotes migration and invasion of HCC cells through inducing EMT. Mechanistically, CMTM6 interacts with and stabilises vimentin, thereby promoting EMT and metastasis of HCC cells.

\section{Methods \\ Cell culture}

Human HCC cell lines were obtained from the Cell Bank of Type Culture Collection of the Chinese Academy of Sciences (Shanghai, China). Roswell Park Memorial Institute (RPMI)-1640 medium containing $100 \mathrm{mg} / \mathrm{ml}$ streptomycin, $100 \mathrm{U} / \mathrm{ml}$ penicillin, and $10 \%$ foetal bovine serum (FBS) Gibco, Mulgrave, Australia) was used for cell culture. Cell culture was maintained under standard cell culture conditions in humidified $5 \% \mathrm{CO}_{2}$.

\section{Patients and specimens}

The present study obtained HCC and adjacent nontumorous tissues from patients with HCC $(n=40)$ who received radical resection in Affiliated Cancer Hospital \& Institute of Guangzhou Medical University (Guangzhou 510515, China). The patients provided signed informed consent for the use of their collected samples, according to the internal review and ethics boards of the Affiliated Cancer Hospital \& Institute of Guangzhou Medical University. Histopathology was used to confirm a diagnosis of HCC.

\section{Lentiviral construction and transduction}

Genechem (Shanghai, China) constructed the U6-shCMTM6-CMV-GFP lentiviral vector, which was used to silence CMTM6 expression. The negative control comprised a lentiviral vector containing a non-silencing short hairpin RNA (shRNA). To silence CMTM6, HCC cells were infected with the lentiviral vector encoding the CMTM6-specific shRNA sequences, control cells were infected with the negative control vector. Puromcyin (Sigma Aldrich, St. Louis, MO, USA) was used to select 
stable clones for 2 weeks. Expression of the CMTM6 protein was detected using western blotting. Additional file 1: Table S1 shows the shRNA sequences.

\section{Small interfering RNA (siRNA) transfection}

RiBoBio (Guangzhou, China) provided the small interfering RNA (siRNA) targeting VIM (encoding vimentin). Cells were seeded into six-well culture plates and grown until they reached $50 \%$ confluence (usually the second day). Lipofectamine 3000 reagent (Invitrogen, Waltham, MA, USA) was used to perform the transfections, as described in the manufacturer's instructions. At $48 \mathrm{~h}$ after transfection, the cells were subjected to functional assays. Western blotting was used to evaluate the transfection efficiency. Additional file 2: Table S2 shows the siRNA sequences.

\section{Quantitative real-time reverse transcription PCR (qRT-PCR)} The TRIzol Reagent (Invitrogen) was used to extract total RNA from HCC cells or tissues, following the manufacturer's guidelines. A SYBR Green PCR kit (Takara Biotechnology, Dalian, China) was used to perform quantitative real-time PCR (qRT-PCR). Data were analysed and normalized to $18 \mathrm{~S}$ rRNA expression. Additional file 3: Table $\mathrm{S} 3$ shows the primer sequences.

\section{Western blotting analysis}

Cell Signaling Technology (Danvers, MA, USA) provided the primary antibodies recognising glyceraldehyde-3-phosphate dehydrogenase [GAPDH (control), CMTM6, N-cadherin, vimentin and E-cadherin]. Total protein was extracted from HCC tissues or cells by lysis using Radioimmunoprecipitation assay (RIPA) buffer containing proteinase and phosphatase inhibitor cocktails (Sigma Aldrich). The proteins were separated using $8 \%$ to $15 \%$ SDS-PAGE and then transferred electrophoretically onto a polyvinylidene fluoride membrane (Invitrogen, Carlsbad, CA, USA). The membranes were blocked using $5 \%$ bovine serum albumin, washed, incubated with primary antibodies at $4{ }^{\circ} \mathrm{C}$ overnight, washed, and incubated with horseradish peroxidase-conjugated goat anti-rabbit or anti-mouse IgG antibody as appropriate. The immunoreactive protein bands were visualised using a chemiluminescence system (Pierce Biotechnology, Rockford, IL, USA).

\section{Tissue multiarray analysis}

Shanghai Outdo Biotech (Shanghai, China) produced tissue microarray sections comprising paired HCC and adjacent non-tumorous tissue samples from 90 patients with HCC. The detailed clinical follow-up data related to outcomes were provided by National Engineering Center Biochip at Shanghai. The follow up began at the date of surgery. Survival was calculated as the time from the baseline date to the clinical outcome diagnosis date or the date of last available clinical record. The patient's history, physical examination, and laboratory tests were evaluated during follow-up, as needed. The time from surgery to death was defined as overall survival (OS).

\section{Cell counting kit-8 (CCK-8) assay}

The CCK- 8 assay was used to assess cell proliferation ability. Cells transfected with siRNAs targeting CMTM6 were seeded into 96 -well plate at of $5 \times 10^{3}$ cells/well. The CCK- 8 solution was used to treat the cells at $0,24,48$, 72 , and $96 \mathrm{~h}$. Absorbance at $570 \mathrm{~nm}$ was tested using a microplate spectrophotometer from triplicate groups.

\section{Colony formation assay}

Cell seeded into 6-well plates were allowed to grow for 12 days. $4 \%$ paraformaldehyde was then used to fix the colonies before staining for $30 \mathrm{~min}$ with $0.1 \%$ crystal violet. The plates were washed with phosphate-buffered saline (PBS), imaged, and the colonies were counted by visual inspection.

\section{Wound-healing assay}

Equal amounts of cells were plated and allowed to grow to $90 \%$ confluence. A sterile pipette tip was used to make a wound in the cell monolayer. The cells on the plate were rinsed gently using medium, which was then replaced with fresh medium. The wound areas were marked and photographed at $0,12,24$, and $48 \mathrm{~h}$ under a phase-contrast microscope. Wound healing was determined by comparison with the wound area at $0 \mathrm{~h}$.

\section{Cell invasion assay}

The cell-invasive assay was performed using 24-well Matrigel invasion chambers with $8 \mu \mathrm{m}$-diameter pore inserts (BD Biosciences, Madrid, Spain). Cells grown in serum-free medium $\left(1.5 \times 10^{5}\right.$ cells $\left./ 100 \mu \mathrm{l}\right)$ were added to the top chamber. $10 \%$ FBS was added to the bottom chamber as a chemoattractant. Over $24 \mathrm{~h}$, the cells were allowed to migrate through the porous membrane. Then, methanol was used to fix the lower chambers, followed by staining with $0.3 \%$ crystal violet for $5 \mathrm{~min}$. After washing with PBS, images were captured under an inverted microscope (Olympus Microscopes, Tokyo, Japan). Cells were counted in five random high power fields in three independent inserts and then averaged.

\section{Immunofluorescence (IF)}

Cells were seeded into glass coverslips in a 12-well plate at a density of $3 \times 10^{4}$ per well. The cells were fixed with paraffin and permeabilized using $0.3 \%$ Triton X-100. Subsequently, the fixed cells were incubated with primary 
antibodies against CMTM6 (Abcam, Cambridge, MA, USA) and Vimentin (Proteintech, Rosemont, IL, USA) overnight at $4{ }^{\circ} \mathrm{C}$, and then incubated with secondary antibodies (Alexa 488 goat anti-Rabbit antibodies; Molecular Probes, Eugene, OR, USA). After counterstaining with Hoechst 33258 (Sigma), images were obtained under a confocal microscopy (Leica Microsystems, Milton Keynes, UK).

\section{Coimmunoprecipitation (Co-IP)}

Myc-tagged vimentin and Flag-tagged CMTM6 expression plasmids were transfected into HCC cells. To precipitate the target proteins, cells were lysed with lysis buffer and incubated with $5 \mu \mathrm{g}$ of the primary antibody, followed by incubation with a slurry of precleared protein agarose bead (Roche, Mannheim, Germany) at $4{ }^{\circ} \mathrm{C}$ for $2 \mathrm{~h}$. After thorough washing, western blotting of the precipitates was used to analyse the potential interacting proteins.

\section{Xenograft studies}

The animal experiments were performed strictly according to the principles and procedures approved by the Committee on the Ethics of Animal Experiments of Guangzhou Medical University (Guangzhou, China). To assess in vivo tumorigenesis, $5 \times 10^{6}$ CMTM6-silenced MHCC-97H cells in of serum-free RPMI $1640(0.1 \mathrm{ml})$ were injected into the left shoulder of 4-week-old female $\mathrm{BALB} / \mathrm{cnu} / \mathrm{nu}$ nude mice subcutaneously (four mice in each group). The size of the resulting tumour was measured weekly. The tumour volumes were calculated using the following formula: (length $\times$ width$\left.^{2}\right) / 2$.

The mice were sacrificed at 32 days after inoculation, and the tumours were dissected and weighed.

To evaluate the mouse liver metastasis potential of cancer cells, $5 \times 10^{6} / 0.2 \mathrm{ml}$ CMTM6-silenced Bel-74029 cells were injected into BALB/c nude mice tail veins (four mice in each group). After 8 weeks, the mice were sacrificed, and the lung metastatic tumours were dissected for further assays. In another group of mice, at 8 weeks after HCC cell injection, the mice were sacrificed and their lungs were removed. An In-Vivo F Imaging System (Kodak, Rochester, NY, USA) was used to assess the metastatic tissues in the lungs after hematoxylin and eosin (H\&E) staining.

\section{Immunohistochemistry (IHC)}

Tissues were fixed in paraformaldehyde and embedded in paraffin. The sections were deparaffinized and hydrated, and then sodium citrate buffer was used to pretreat the sections by heating in a microwave to retrieve the antigen, followed by blocking with normal goat serum. Rabbit anti-CMTM6, anti-Vimentin or anti-Ki67 antibodies
(Cell Signaling Technology) were then incubated with the sections at $4{ }^{\circ} \mathrm{C}$ overnight. The next day, biotinylated goat anti-rabbit IgG secondary antibodies were incubated with the sections at room temperature $\left(19-21{ }^{\circ} \mathrm{C}\right)$ for $1 \mathrm{~h}$. Lastly, avidin-biotin peroxidase complex (GeneTex, Irvine, CA, USA) was used to stain the sections. Staining intensity was assessed using a semi-quantitative approach ( 0 , negative; 1 , weak; and 2 , strong) and the percentage of positively stained malignant cells was scored as: 0 , $0-4 \%$; $1,5-24 \%$; $2,25-49 \%$; 3, 50-74\%; and 4, 75-100\%. The final IHC scores were determined by multiplying the intensity score by the percentage counts. Positive expression of CMTM6 was defined as having an IHC score $\geq 3$.

\section{Statistical analysis}

All statistical data are shown as the mean \pm the standard deviation (SD). Student's t-test or analysis of variance (ANOVA) were used to perform the statistical analyses. To analyse the relation of CMTM6 expression with the clinicopathological characteristics of the patients, the chi-squared test was used. Survival analyses were assessed using the Kaplan-Meier plotter. SPSS 19.0 software (IBM Corp, Armonk, NY, USA) was used for all statistical analyses. $\mathrm{P}<0.05$ was considered to indicate statistical significance.

\section{Results \\ CMTM6 is upregulate in HCC}

First, we used qRT-PCR to detect the mRNA expression of CMTM6 in 40 paired human HCC tissues and matched adjacent normal tissues, which showed that the relative mRNA expression CMTM6 was upregulated in $75 \%(30 / 40)$ of patients with HCC (Fig. 1a). CMTM6 mRNA expression was increased significantly in HCC tissues compared with that in the adjacent normal tissues (Fig. 1b). Furthermore, CMTM6 levels were upregulated significantly in 12 pairs $\mathrm{HCC}$ tissues compared with the adjacent normal tissues, as assessed using western blotting (Fig. 1c). Moreover, IHC results also revealed that CMTM6 expression was higher in HCC tissues compared with that in the matched adjacent normal tissues (Fig. 1d). These results indicated upregulated expression of CMTM6 in HCC tissues.

\section{CMTM6 promotes $\mathrm{HCC}$ cell proliferation, migration, and invasion in vitro}

Given that CMTM6 is upregulated in HCC, to investigate the biological functions of CMTM6 in HCC cells, we performed loss-and gain-of-function experiments. First, we determined that CMTM6 is commonly expressed in HCC cells (Fig. 2a). Next, MHCC-97H and BEL-7402 cells with high expression of CMTM6 were transduced with lentiviruses encoding the CMTM6 shRNA to inhibit 


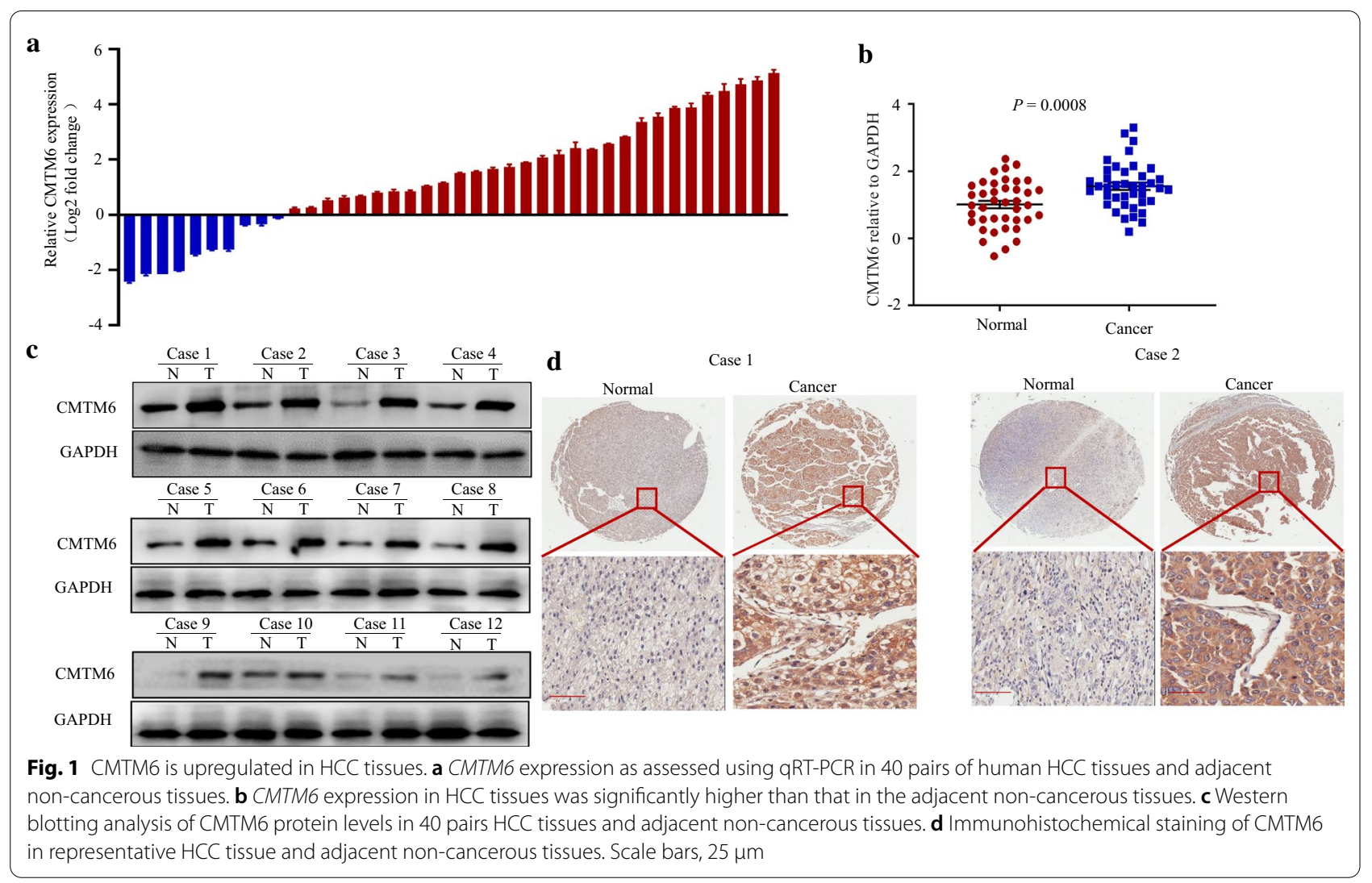

CMTM6 expression (Fig. 2b). Interestingly, silencing CMTM6 decreased the proliferative capacity of HCC cells significantly, as assessed using CCK- 8 and colony formation assays (Fig. 2c, d). Moreover, CMTM6 silencing decreased HCC cell invasion and migration, according to Transwell and wound-healing assays (Fig. 2e, f). By contrast, overexpression of CMTM6 in HCCLM3 cells with low endogenous CMTM6 expression increased the proliferative capacity of HCCLM3 cells significantly (Fig. 2g-i). Importantly, Transwell assays showed that overexpression of CMTM6 enhanced the invasion of HCCLM3 cells (Fig. 2j). Similarly, in a wound-healing assay, overexpression of CMTM6 led to increased migration potential (Fig. 2k). Thus, in HCC cells, CMTM6 enhances invasion, migration, and proliferation.

\section{CMTM6 silencing reduces in vivo HCC cell proliferation and tumour metastasis}

To investigate the in vivo effect of CMTM6 on tumour growth, lentivirus-mediated shRNA targeting CMTM6transduced cells and control MHCC-97H cells were injected subcutaneously into nude mice's right shoulders (Fig. 3a). Four weeks later, the size of the tumour in the CMTM6 knockdown group was considerably decreased compared with that in the control group (Fig. 3b). We observed that in the CMTM6 knockdown group, the tumour cells were arranged more loosely (as shown by $\mathrm{H} \& \mathrm{E}$ staining), and the expression of $\mathrm{Ki}-67$ had decreased significantly (Fig. 3c, d). These results indicated that knockdown of CMTM6 inhibits the growth and tumorigenicity of HCC cells in vivo.

Next, to determine whether CMTM6 could promote in vivo metastasis, we performed a tail vein metastatic assay in nude mice using Bel-7402 cells that were transduced with lentivirus encoding the CMTM6 shRNA or empty vector. Five-week-old nude mice were injected via their tail-veins with Bel-7402 cells with CMTM6 knockdown or control cells. At 6 weeks post-injection, the CMTM6 silenced group had fewer metastatic lesions in their lungs compared with those in the mice who received the control cells (Fig. 3e). Finally, The lung metastatic nodules of the control group mice became larger and larger, while the mice injected with shCMTM6 cells had fewer and fewer metastatic nodules (Fig. 3f, g). These results indicated that knockdown of CMTM6 reduces the metastatic potential of $\mathrm{HCC}$ cells in vivo.

\section{CMTM6 induces EMT in HCC cell}

Tumour invasion and metastasis depend on EMT; therefore, we detected the levels of EMT markers to assess 


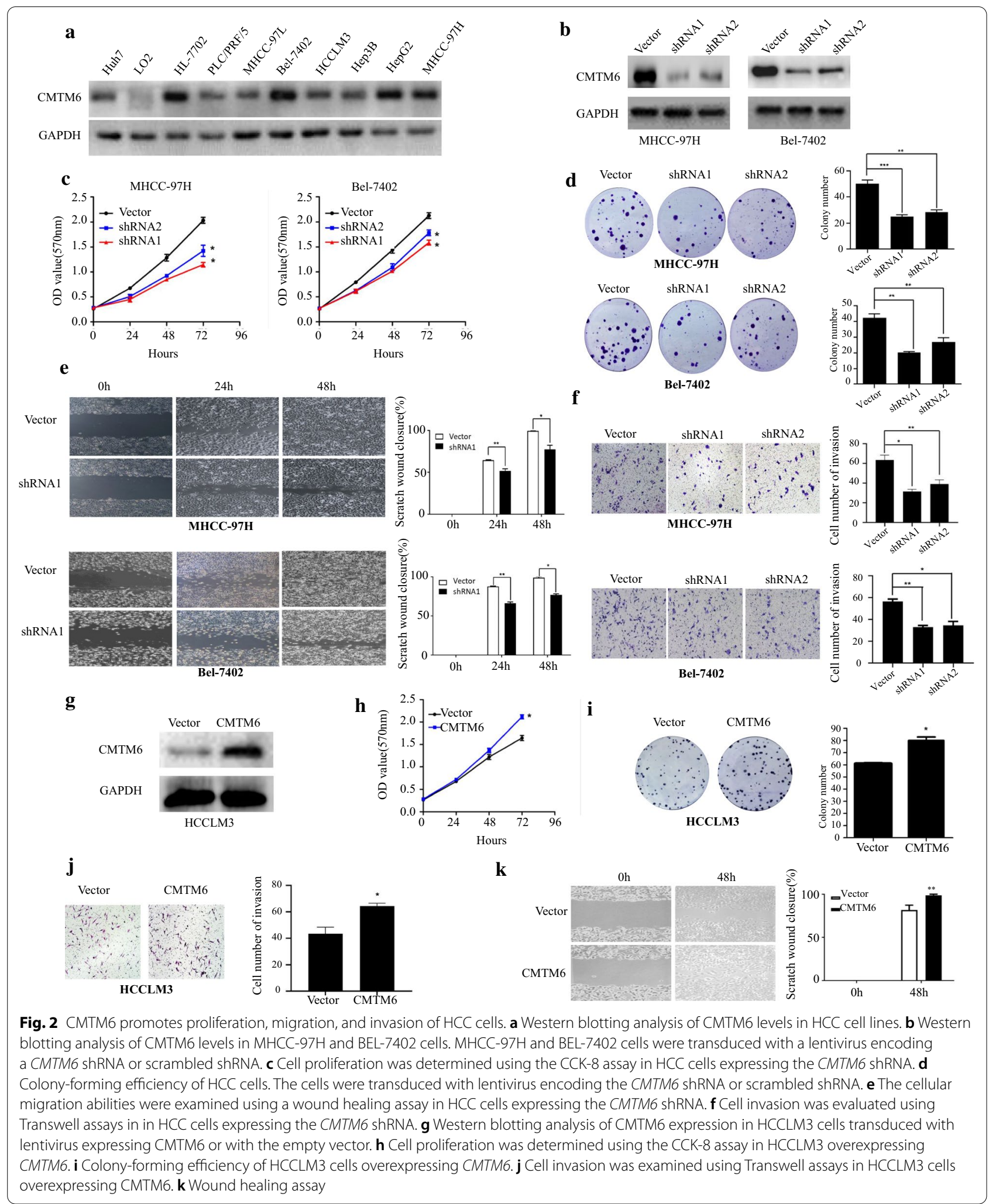


the effect of CMTM6 knockdown on EMT. CMTM6 knockdown enhanced the levels of the epithelial marker E-cadherin, but decreased the levels of the mesenchymal markers vimentin and N-cadherin (Fig. 4a). Moreover, CMTM6 knockdown resulted in morphological change to HCC cells, which underwent a transformation from a mesenchymal phenotype to an epithelial phenotype (Fig. 4b). Conversely, CMTM6 overexpression decreased E-cadherin levels, and increased vimentin and $\mathrm{N}$-cadherin levels in HCC cells (Fig. 4c). Consistently, cells overexpressing CMTM6 exhibited a spindle shape and stretched F-actin fibres, which are characteristic of the EMT process (Fig. 4d). These results indicated that CMTM6 promotes EMT in HCC cells.

\section{CMTM6 interacts with vimentin to induce EMT and promote metastasis of $\mathrm{HCC}$ cells}

To investigate how CMTM6 induces EMT in HCC cells, the STRING database was used to perform proteinprotein interaction analysis. Interestingly, this analysis identified that vimentin might interact with CMTM6 (Fig. 4e). Vimentin, expressed by interstitial cells, decreases adhesion between tumour cells, and increases their invasiveness and migration [16]. Upregulation of vimentin induces EMT, thus contributing to migration and invasion [17]. For instance, FOXK1 interacts with and stabilises vimentin, thereby promoting gastric cancer cell migration and metastasis via the induction of EMT [18]. We hypothesized that CMTM6 interacts with and stabilises vimentin, which in turn induces EMT and promotes the migration and invasion of HCC cells. To verify the physical interaction between CMTM6 and vimentin, reciprocal coimmunoprecipitation experiments were performed. The results confirmed that vimentin and CMTM6 interacted in HCC cell lysates (Fig. 4f). Moreover, vimentin and CMTM6 were observed to colocalise in HCC cells under confocal fluorescence microscopy (Fig. 4g).

To determine whether CMTM6 increases the stability of vimentin, protein synthesis was inhibited in HCC cells using cycloheximide (CHX), and the remaining vimentin level was analysed using western blotting. The level of vimentin in cell overexpressing CMTM6 remained higher than that in the control cells (Fig. 4h). Importantly, CMTM6 overexpression caused the half-life of endogenous vimentin to increase from 4 to almost $9 \mathrm{~h}$ (Fig. 4i). These results suggested that CMTM6 overexpression stabilised vimentin.

We sought to confirm whether CMTM6 could regulate EMT through vimentin. After VIM was silenced in cells overexpressing CMTM6, the expression of EMT epithelial marker, E-cadherin, increased (Fig. 5a), which suggested that suppression of vimentin blocked the EMT induced by CMTM6 overexpression. Furthermore, a colony formation assay showed that the induction of proliferation by CMTM6 overexpression was blocked by vimentin inhibition (Fig. 5b). Moreover, Transwell assays showed that knockdown of VIM reversed CMTM6induced invasion and migration (Fig. 5c, d). Collectively, the findings showed that CMTM6 enhances proliferation, metastasis, and EMT at least partly dependent on vimentin.

\section{Co-expression of CMTM6 and vimentin correlates with poor prognosis in $\mathrm{HCC}$}

We analysed the associated clinicopathological features in HCC to determine the clinical relevance of CMTM6 with vimentin. CMTM6 and vimentin proteins levels were significantly higher in HCC tissues compared with those in adjacent noncancerous tissues (Fig. 6a, b). CMTM6 and vimentin expression correlated positively in HCC specimens $(P<0.001)$ (Fig. 6c). Importantly, CMTM6 was significantly associated with TNM stage $(P=0.048)$, HbsAg $(P=0.012)$, tumour differentiation $(P=0.039)$, tumour size $(P=0.024)$, and microvascular invasion $(P=0.04)$. Vimentin expression correlated markedly with TNM stage $(P=0.003)$, tumour differentiation $(P=0.001)$, tumour size $(P=0.024)$, and microvascular invasion $(P=0.013)$ (Table 1$)$.

Moreover, univariate Cox regression analysis indicated that microvascular invasion (95\% confidence interval (CI) 1.162-5.277; $P=0.019$ ), differentiation (95\% CI 1.218$3.830 ; P=0.008)$, TNM stage $(95 \%$ CI $1.088-5.407$; $P=0.030$ ), CMTM6 expression (95\% CI 0.997-5.906; $P=0.041$ ), and vimentin expression (95\% CI 1.007-5.005; $P=0.048$ ) could predict OS in patients with HCC. Subsequent multivariate Cox regression analysis showed that differentiation (95\% CI $0.309-0.856 ; P=0.011)$, CMTM6 (95\% CI 1.118-7.096; $P=0.006)$, vimentin (95\% CI 1.391-7.340; $P=0.037)$ remained predictive factors.

\footnotetext{
(See figure on next page.)

Fig. 3 Knockdown of CMTM6 inhibits HCC cell proliferation and metastasis in vivo. a Images of mice injected with CMTM6-silenced MHCC-97H cells. b, $\mathbf{c} 1 \mathrm{HC}$ and Ki-67 expression in tumours from mice injected with HCC cells. d Tumour weight of model mice; the tumours were lighter in the mice that received cells silenced for CMTM6 expression than in those that received cells transduced with the empty vector. Tumour weights are indicated by the data points. e Fluorescence images of metastatic lung nodules of mice injected with Bel-7402 cells silenced for CMTM6. $\mathbf{f}$ Representative H\&E staining of lung metastasis nodules. $\mathbf{g}$ The number of lung metastatic loci. Student $t$ test was used to analyse the number of metastatic nodules. $\mathbf{h}$ The expression of Ecadherin in tumors was determined using quantitative PCR (qPCR). ${ }^{* *} p<0.001$, vector vs. shCMTM6
} 
a
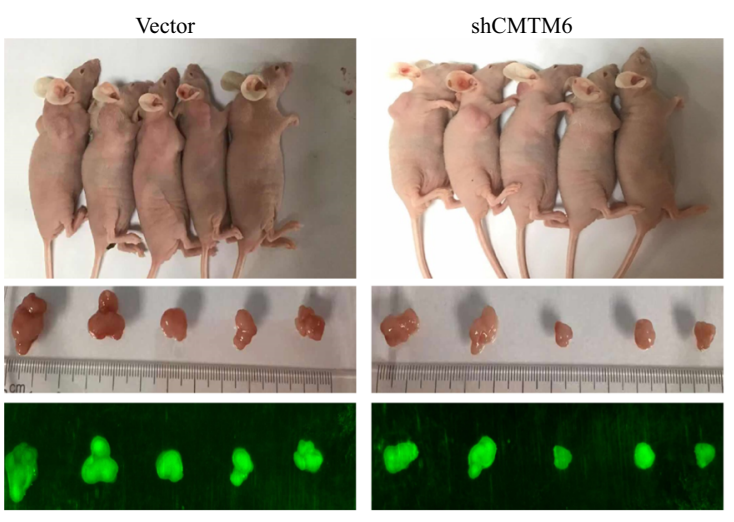

c
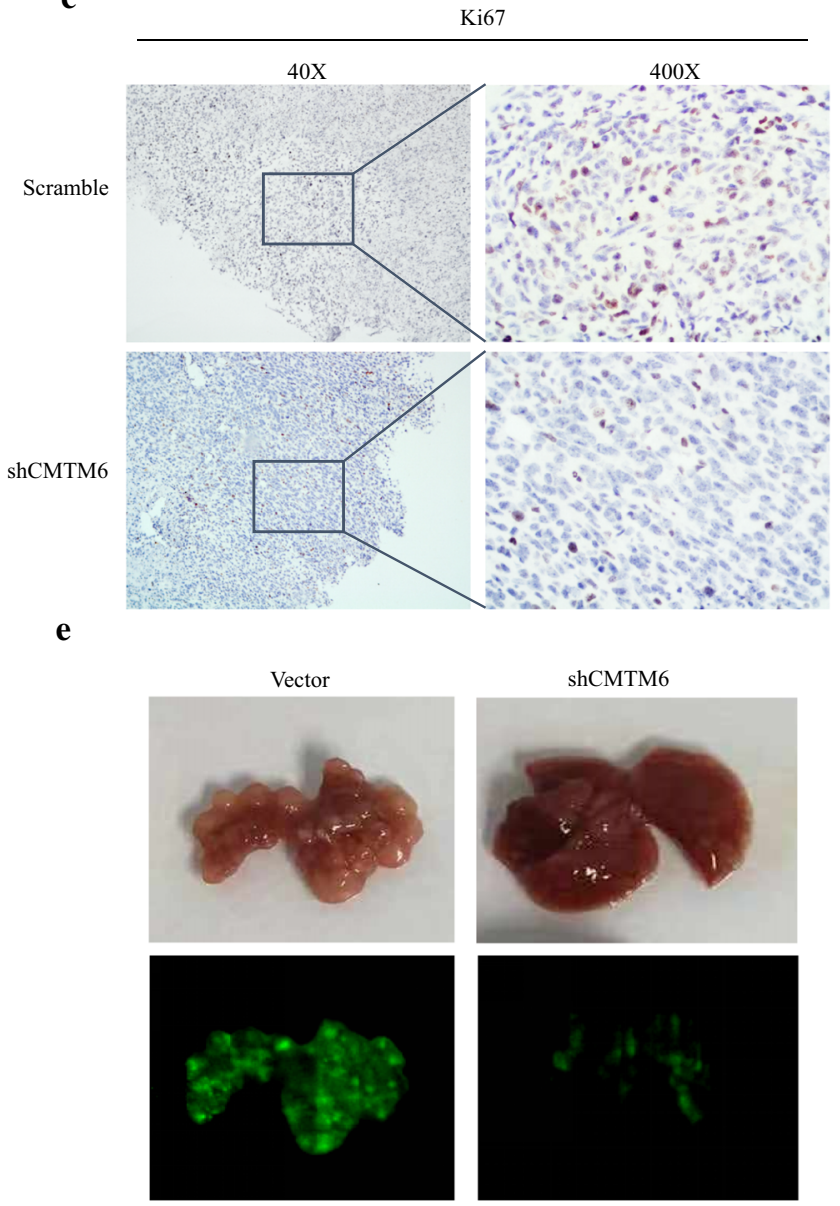

g
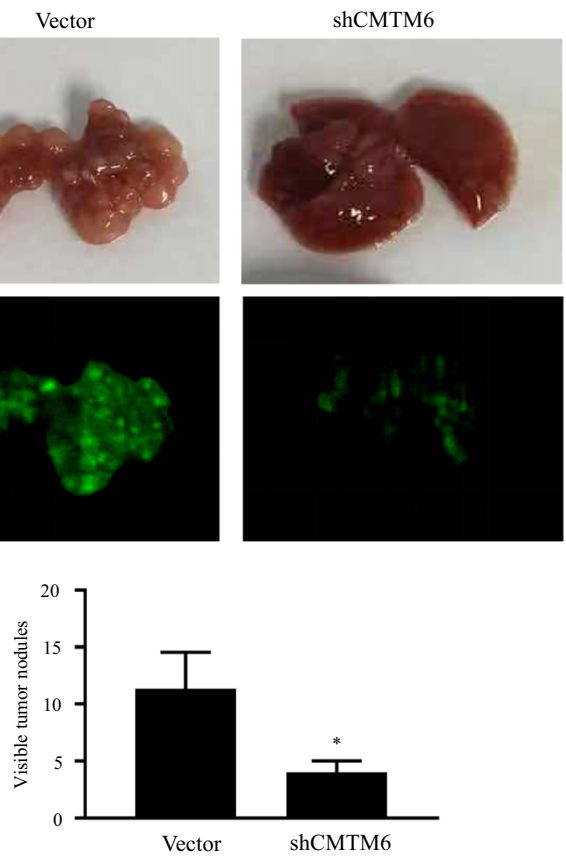

b

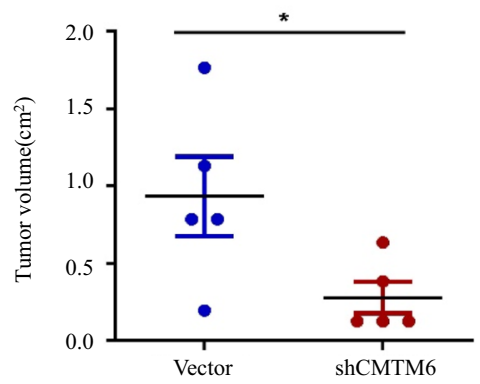

d

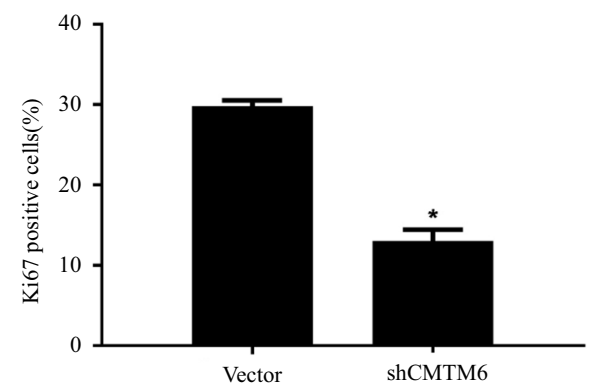

f
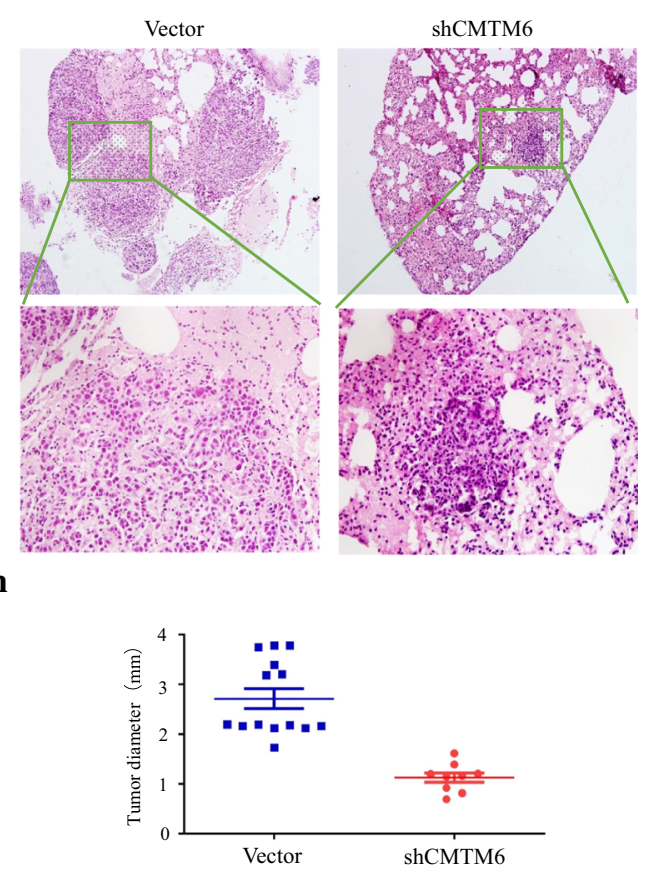
Interestingly, the combined expression of CMTM6 and vimentin (95\% CI 0.826-3.908; $\mathrm{P}=0.040)$ was identified as an independent prognostic factor for OS (Table 2) in patients with HCC. The Kaplan-Meier analysis for combined CMTM6 and vimentin revealed that patients with higher CMTM6 and vimentin levels had the shortest post-operative OS (Fig. 6d).

\section{Discussion}

The results of the present study revealed upregulation of CMTM6 in HCC tissue samples compared with that in adjacent normal liver tissues. Silencing of CMTM6 expression suppressed the proliferation, migration, and invasion of HCC cell, whereas CMTM6 had the opposite effects. CMTM6 interacts and stabilises vimentin to induce EMT of HCC cells, thereby promoting proliferation, invasion, and migration. Poorer prognosis if HCC is associated significantly with higher CMTM6 expression. Thus, the CMTM6-vimentin axis has an important function in HCC.

Previous studies showed that CMTM6 participates in tumorigenesis $[7,19]$. Herein, IHC and western blotting were used initially to detect CMTM6 expression in HCC samples. CMTM6 was highly expressed in HCC, which suggested that CMTM6 overexpression might be associated with HCC tumour progression. Subsequently, we found that silencing of CMTM6 markedly inhibited HCC cell invasion and migration and CMTM6 overexpression had the opposite effects. Importantly, in the xenograft mouse model, CMTM6 knockdown markedly reduced subcutaneous solid tumour growth and the number of pulmonary metastasis nodules. These data indicated that CMTM6 promotes HCC progression and development. Many studies have explored the relationship between CMTM6 and tumour immunity, indicating that CMTM6 as a promising target for cancer immunotherapy $[8,9]$. The results of the present study implicated CMTM6 in the migration and invasion of HCC cells, thus improving our understanding of CMTM6's function in tumours and suggesting that CMTM6 is a therapeutic target to treat HCC.
Cancer cell migration and invasion rely on EMT, during which epithelial markers (E-cadherin, ZO-1, and Occludin) are downregulated, whereas mesenchymal markers (vimentin, $\mathrm{N}$-cadherin, and Fibronectin) are upregulated [20]. A previous study reported that CMTM6 is involved in EMT regulation in head and neck squamous cell carcinoma [6]; however, whether CMTM6 is implicated in EMT in HCC cells is largely unknown. In this study, we observed that knockdown of CMTM6 enhanced the expression of E-cadherin, epithelial marker, but decreased the expression vimentin and $\mathrm{N}$-cadherin (mesenchymal markers). By contrast, CMTM6 overexpression decreased E-cadherin expression and increased vimentin and $\mathrm{N}$-cadherin expression. Morphologically, HCC cells silenced for CMTM6 expression resembled epithelial cells, while the control cells maintained a spindle-like mesenchymal cell morphology. Therefore, these results indicated that CMTM6 promotes EMT in HCC cells.

Vimentin is considered as a protein marker of EMT reprogramming, in which cancer cells acquire migratory and invasive phenotypes [16, 21]. Increased expression of vimentin has been observed in colorectal, breast, gastric, and hepatic cancers [22-25]. High expression of vimentin correlates with the aggressiveness and poor clinical outcome in many types of cancers [26, 27]. Therefore, targeting vimentin is a promising approach for anti-cancer therapy. Several factors were reported to be involved in the regulation of vimentin expression [28-30]. For example, EMT-related transcription factors nuclear factor kappa B (NF- $\mathrm{kB}$ ) and Jun proto-oncogene, AP-1 transcription factor subunit (AP-1/jun) can bind to the VIM promoter and induce vimentin expression, thus promoting tumour cell migration and invasion [30,31]. Circular RNs circ-10720 increased the vimentin expression levels and promoted EMT by sponging microRNAs that target VIM (17). Importantly, circ-10720 expression correlated positively with vimentin expression in patients with $\mathrm{HCC}$ [32].

The present study revealed that CMTM6 overexpression enhanced the invasion, proliferation, and EMT of $\mathrm{HCC}$ cells via its interaction and stabilisation of vimentin. Our data indicated that CMTM6-induced migration,

\footnotetext{
(See figure on next page.)

Fig. 4 CMTM6 promotes EMT in HCC cells. a The levels of vimentin, N-cadherin, and E-cadherin in HCC cells silenced for CMTM6 expression, as assessed using western blotting. b Representative morphology of MHCC-97H cells silenced for CMTM6 expression. $\mathbf{c}$ The levels of vimentin, $\mathrm{N}$-cadherin, and E-cadherin in HCCLM3 and C3A cells overexpressing CMTM6, as assessed using western blotting. $\mathbf{d}$ F-actin filament staining using rhodamine phallotoxin staining for $48 \mathrm{~h}$ in HCCLM3 cells stably overexpressing CMTM6 or empty vector, as assessed using fluorescence microscopy. e STRING database analysis to predict potential binding partners of CMTM6. fThe interaction between CMTM6 and vimentin in Bel-7402 and MHCC-97H cells, as determined using Co-IP. Anti-CMTM6 or anti-Vimentin antibodies were used to immunoprecipitate the lysates. Western blotting was used to analyse the input and the immunoprecipitates using the indicated antibodies. $\mathbf{g}$ CMTM6 and vimentin double staining HCC cells, as assessed using confocal microscopy. h, i CHX $(20 \mu \mathrm{g} / \mathrm{ml})$ treatment for various times of HCCLM3 cells overexpressing CMTM6 or transduced with the empty vector. Western blotting was used to analyse the proteins in whole-cell extracts
} 


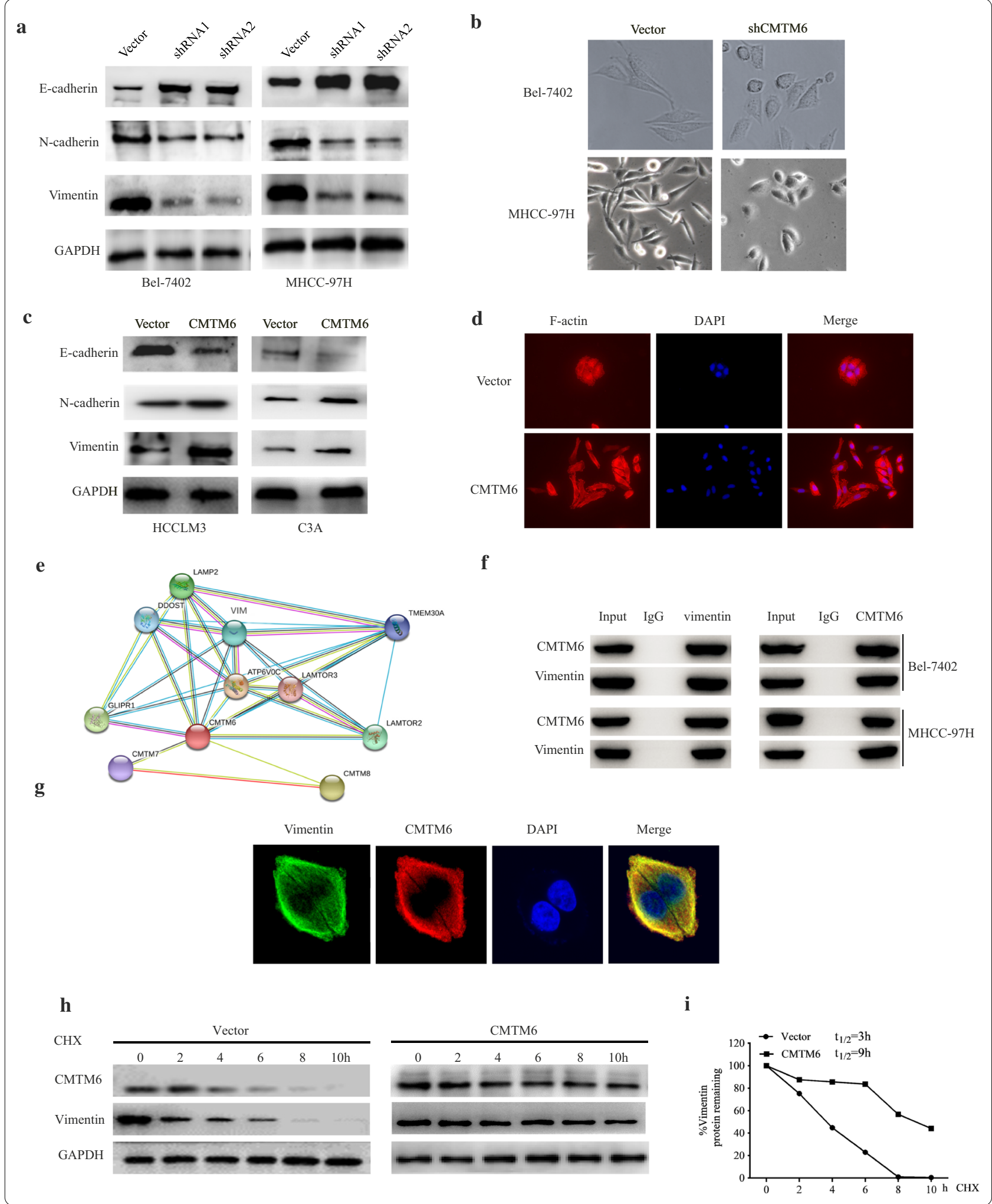




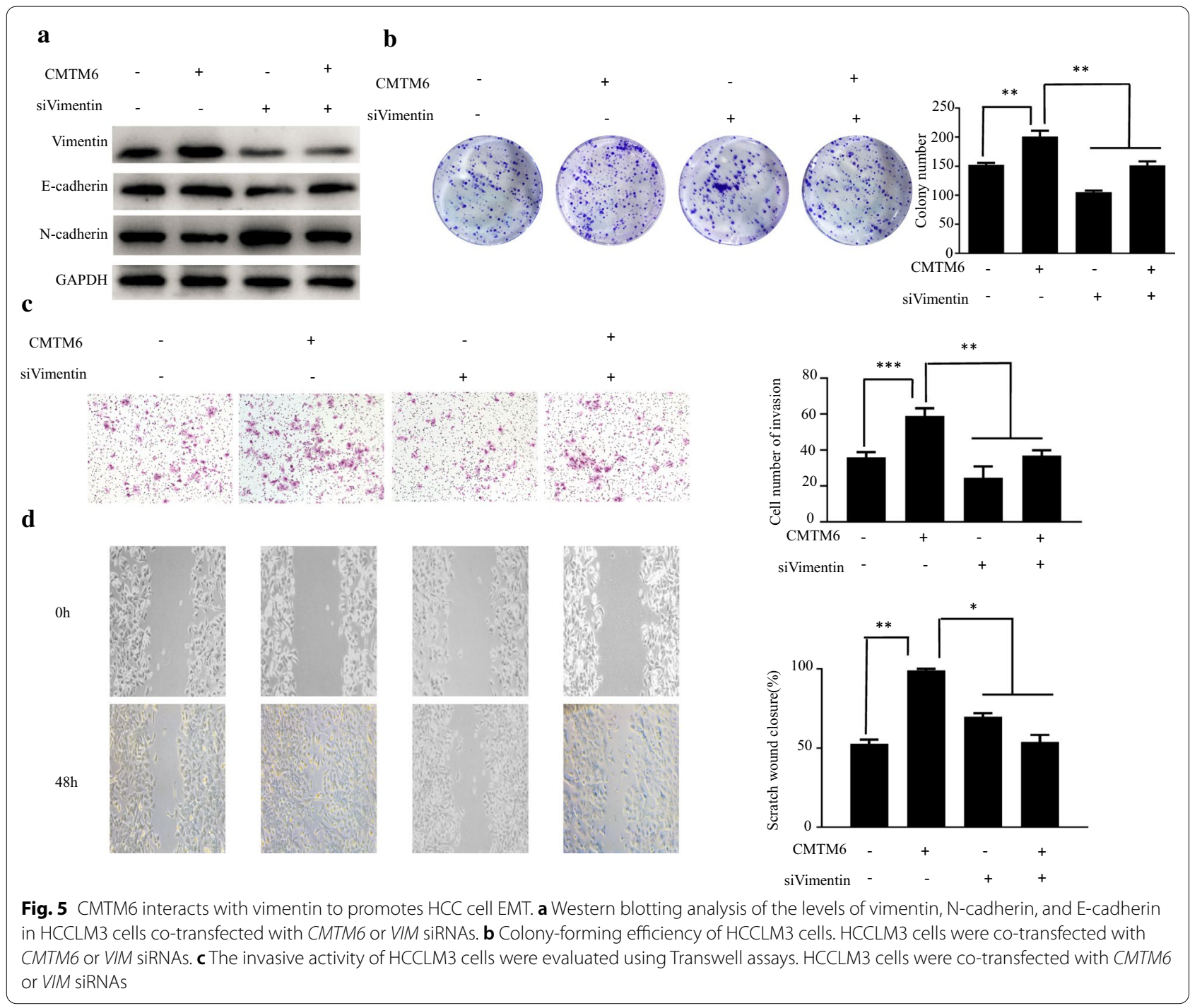

invasion, and EMT could be blocked by VIM knockdown, suggesting that CMTM6 promotes migration, invasion and EMT, at least partly dependent on vimentin. Importantly, we detected a positive correlation between the expression of CMTM6 and vimentin in HCC tissues. The survival time of the patients with positive CMTM6 and vimentin expression was significantly shorter than that of patients with negative expression. Therefore, in HCC, the synergistic effects of vimentin and CMTM6 might be especially important. In addition, the CMTM6 or vimentin level, or both, might be developed as biomarkers for the high likelihood of poor prognosis and tumour metastasis in patients with HCC. Further investigation is required to determine CMTM6's specific regulatory mechanism in the stabilization of vimentin, the progression of EMT, and the vimentin-interacting region of CMTM6 in HCC cells.

\section{Conclusions}

The results demonstrated that CMTM6 was upregulated in HCC tissue samples compared with that in adjacent normal liver tissues. CMTM6 contributed to migration, invasion, and EMT of HCC cells. Mechanistically, CMTM6 physically interacts with and stabilizes vimentin, thus inducing EMT and promoting proliferation, migration, and invasion. We identified a significant association between poorer prognosis of HCC and higher CMTM6 expression. Our findings indicated that CMTM6 has important functions in the growth and metastasis of HCC through its interaction with, and stabilisation of, vimentin. Thus, CMTM6 could be developed as a biomarker and target molecule for $\mathrm{HCC}$ therapy. 


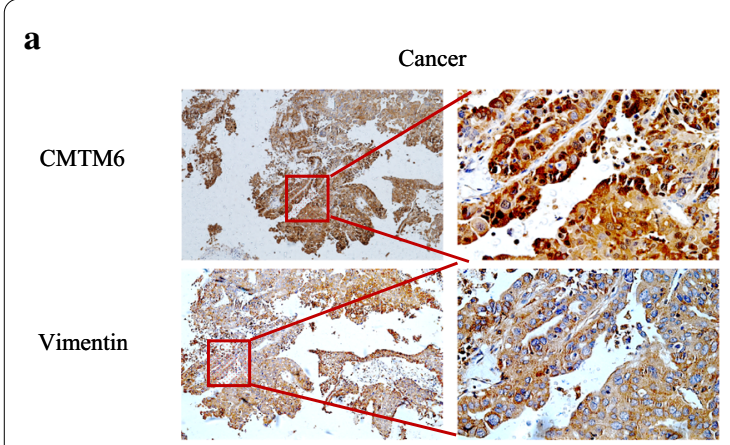

b
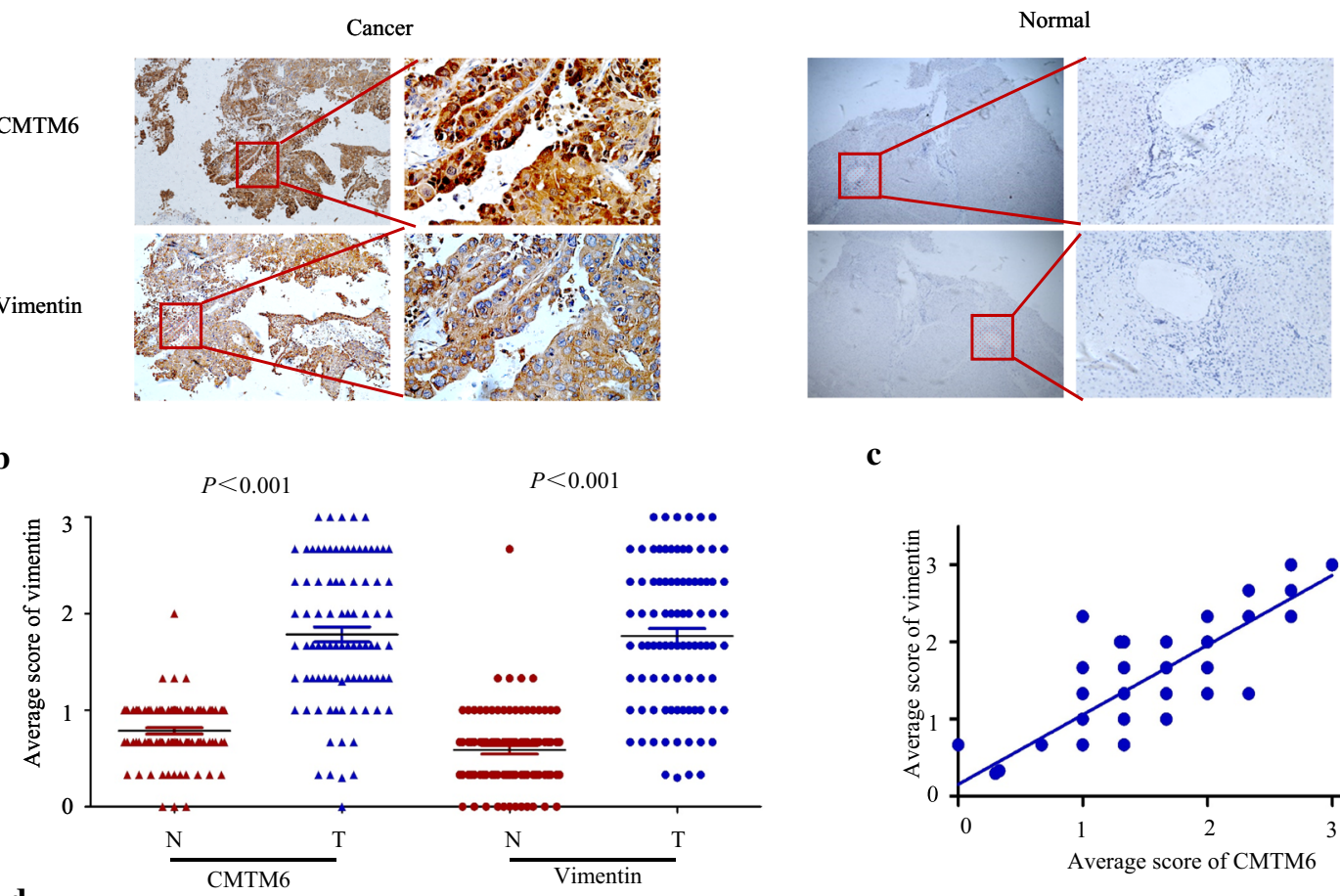

c
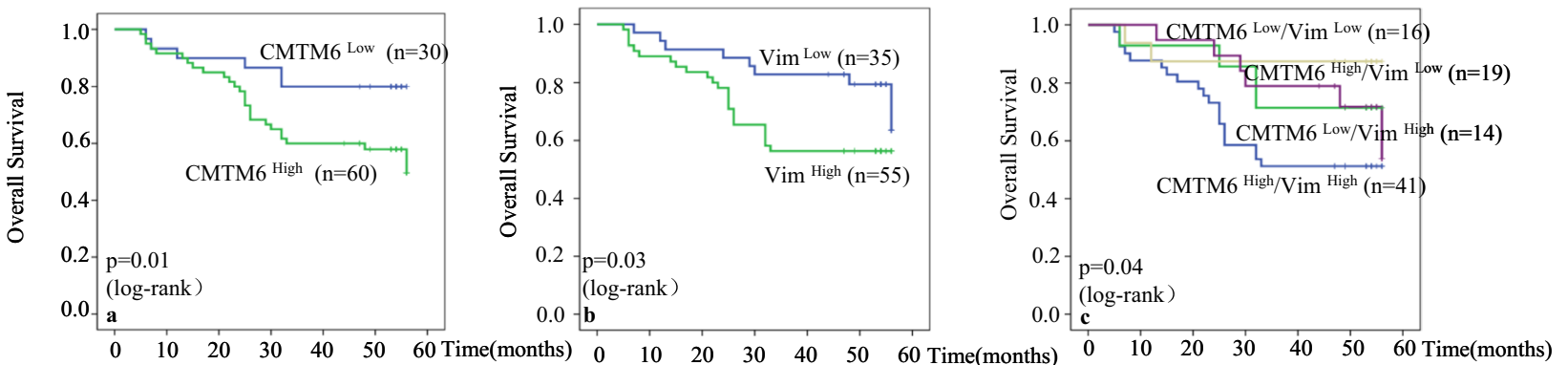

Fig. 6 Co-expression of vimentin and CMTM6 correlates with poor prognosis in HCC. a IHC analysis of CMTM6 and vimentin levels in in HCC tissues. b The average staining scores in cancerous and normal tissues of CMTM6 and vimentin. c Quantification of positive staining for CMTM6 and vimentin, and Spearman rank correlation coefficient analysis of their correlation. $\mathbf{d}$ Overall survival analysis of CMTM6 alone, vimentin alone, combined CMTM6/vimentin expression using the Kaplan-Meier method 
Table 1 Correlation between CMTM6/vimentin protein expression and the clinicopathological characteristics of patients with HCC $(n=90)$

\begin{tabular}{|c|c|c|c|c|c|c|c|}
\hline \multirow[t]{2}{*}{ Features } & \multirow{2}{*}{$\begin{array}{l}\text { Total number } \\
(n=90)\end{array}$} & \multicolumn{2}{|c|}{ Expression of CMTM6 } & \multirow[t]{2}{*}{$P$-value } & \multicolumn{2}{|c|}{ Expression of vimentin } & \multirow[t]{2}{*}{$P$-value } \\
\hline & & Low & High & & Low & High & \\
\hline \multicolumn{8}{|l|}{ Age(years) } \\
\hline$<60$ & 68 & $21(30.9 \%)$ & 47 (69.1\%) & 0.386 & $24(35.3 \%)$ & $44(64.7 \%)$ & 0.219 \\
\hline$\geq 60$ & 22 & $9(40.9 \%)$ & $13(59.1 \%)$ & & $11(50.0 \%)$ & $11(50.0 \%)$ & \\
\hline \multicolumn{8}{|l|}{ Gender } \\
\hline Male & 80 & 27 (33.8\%) & $53(66.3 \%)$ & 0.813 & $32(40.0 \%)$ & $48(60.0 \%)$ & 0.541 \\
\hline Female & 10 & $3(30.0 \%)$ & $7(70.0 \%)$ & & $3(30.0 \%)$ & $7(70.0 \%)$ & \\
\hline \multicolumn{8}{|c|}{ Microvascular invasion } \\
\hline Present & 54 & $23(42.6 \%)$ & $31(57.4 \%)$ & $0.04^{*}$ & $26(48.1 \%)$ & $35(51.9 \%)$ & $0.013^{*}$ \\
\hline Absent & 26 & $5(19.2 \%)$ & $21(80.8 \%)$ & & $5(19.2 \%)$ & $21(80.8 \%)$ & \\
\hline \multicolumn{8}{|c|}{ Tumour size(cm) } \\
\hline$<5$ & 51 & $22(43.1 \%)$ & $29(56.9 \%)$ & $0.024^{*}$ & $25(49.0 \%)$ & $26(51.0 \%)$ & $0.024^{*}$ \\
\hline$\geq 5$ & 39 & $8(20.5 \%)$ & 31 (79.5\%) & & $10(25.6 \%)$ & $29(74.4 \%)$ & \\
\hline \multicolumn{8}{|c|}{ Differentiation } \\
\hline Well & 15 & $9(60.0 \%)$ & $6(40.0 \%)$ & $0.039^{*}$ & $12(80.0 \%)$ & $3(20.0 \%)$ & $0.001^{*}$ \\
\hline Moderate & 38 & $10(26.3 \%)$ & $28(73.7 \%)$ & & 11 (28.9\%) & $27(71.1 \%)$ & \\
\hline Poor & 31 & $8(25.8 \%)$ & $23(74.2 \%)$ & & $8(25.8 \%)$ & $23(74.2 \%)$ & \\
\hline \multicolumn{8}{|l|}{ HBsAg } \\
\hline Negative & 19 & 11 (57.9\%) & $8(42.1 \%)$ & $0.012^{*}$ & $6(31.6 \%)$ & 13 (68.4\%) & 0.436 \\
\hline Positive & 70 & 19 (27.1\%) & 51 (72.9\%) & & $29(41.4 \%)$ & 41 (58.6\%) & \\
\hline \multicolumn{8}{|c|}{ Serum AFP level (ng/ml) } \\
\hline$<25$ & 39 & 9 (23.1\%) & 30 (76.9\%) & 0.061 & 16 (41.0\%) & 23 (59.0\%) & 0.772 \\
\hline$\geq 25$ & 50 & $21(42.0 \%)$ & $29(58.0 \%)$ & & 19 (38.0\%) & 31 (62.0\%) & \\
\hline \multicolumn{8}{|l|}{ TNM stage } \\
\hline$|+| \mid$ & 78 & 29 (37.2\%) & 49 (62.8\%) & $0.048^{*}$ & 35 (44.9\%) & $43(55.1 \%)$ & $0.003^{*}$ \\
\hline$I I I+I V$ & 12 & $1(8.3 \%)$ & 11 (91.7\%) & & $0(0.0 \%)$ & 12 (100.0\%) & \\
\hline
\end{tabular}

${ }^{*} p<0.05$

Table 2 Univariate and multivariate analyses of different prognostic factors in 90 patients with HCC

\begin{tabular}{|c|c|c|c|c|}
\hline \multirow[t]{2}{*}{ Features } & \multicolumn{2}{|l|}{ Univariate analysis } & \multicolumn{2}{|l|}{ Multivariate analysis } \\
\hline & HR $(95 \% \mathrm{Cl})$ & P-value & $\mathrm{HR}(95 \% \mathrm{Cl})$ & P-value \\
\hline Age (years; $<60$ vs. $\geq 60$ ) & $1.298(0.600-2.807)$ & 0.508 & & \\
\hline Sex (male vs. female) & $0.520(0.124-2.176)$ & 0.371 & & \\
\hline Microvascular invasion (absent vs. present) & $2.476(1.162-5.277)$ & $0.019^{*}$ & & \\
\hline Tumour size $(\mathrm{cm} ;<5$ vs. $\geq 5)$ & $1.928(0.952-3.904)$ & 0.068 & & \\
\hline Differentiation (well, moderate, poor) & $2.160(1.218-3.830)$ & $0.008^{*}$ & $0.514(0.309-0.856)$ & $0.011^{*}$ \\
\hline HBsAg (positive vs. negative) & $1.270(0.516-3.124)$ & 0.603 & & \\
\hline $\operatorname{AFP}(<25$ vs.$\geq 25)$ & $1.607(0.770-3.356)$ & 0.206 & & \\
\hline TNM stage (I+ II vs. III + IV) & $2.425(1.088-5.407)$ & $0.030^{*}$ & & \\
\hline Expression of CMTM6 (low vs. high) & $2.427(0.997-5.906)$ & $0.041^{*}$ & $2.816(1.118-7.096)$ & $0.006^{*}$ \\
\hline Expression of vimentin (low vs. high) & $2.245(1.007-5.005)$ & $0.048^{*}$ & $3.196(1.391-7.340)$ & $0.037^{*}$ \\
\hline \multicolumn{5}{|l|}{ Co-expression } \\
\hline $\begin{array}{l}\text { CMTM6 (high) vimentin (high) } \\
\text { CMTM6 (high) vimentin (low) } \\
\text { CMTM6 (low) vimentin (high) } \\
\text { CMTM6 (low) vimentin (low) }\end{array}$ & $0.716(0.519-0.987)$ & $0.042^{*}$ & $1.796(0.826-3.908)$ & $0.040^{*}$ \\
\hline
\end{tabular}




\section{Abbreviations}

HCC: Hepatocellular carcinoma; CMTM6: CKLF Like MARVEL Transmembrane Domain Containing 6; qRT-PCR: Quantitative real-time reverse transcription PCR; IHC: Immunohistochemistry; IF: Immunofluorescence; Co-IP: Co-immunoprecipitation; EMT: Epithelial-mesenchymal transition; CCK-8: Cell counting kit-8; siRNA: Small interfering RNA; CSCs: Cancer stem cells; shRNA: Short hairpin RNA.

\section{Supplementary Information}

The online version contains supplementary material available at https://doi. org/10.1186/s12967-021-02787-5.

Additional file 1: Table $\mathbf{S} 1$. Sequences of shRNAs.

Additional file 2: Table S2. Sequence of siRNAs ( $5^{\prime}$ to $\left.3^{\prime}\right)$.

Additional file 3: Table S3. Sequences of qRT-PCR primers.

\section{Acknowledgements}

We sincerely thank Dr. Jide Wang for providing encouragement.

\section{Authors' contributions}

XH performed the experiments. YY, DY designed the experiments. BW performed the IHC analysis. LX and YT was a major contributor in writing the manuscript. All authors read and approved the final manuscript.

\section{Funding}

The present study received financial support from the National Natural Science Foundation of China (Grant Number 81872195); the Natural Science Foundation of Guangdong Province (Grant Number 2020A1515010208).

\section{Availability of data and materials}

All data generated or analyzed during this study are included in this published article.

\section{Declartions}

\section{Ethics approval and consent to participate}

The present study was approved by the Ethics Committee and Institutional Review Board of affiliated Cancer Hospital \& Institute of Guangzhou Medical University.

\section{Consent for publication}

Not applicable.

\section{Competing interests}

The authors declare that they have no competing interests.

\begin{abstract}
Author details
${ }^{1}$ Department of Radiation Oncology, Affiliated Cancer Hospital \& Institute of Guangzhou Medical University, No. 78 Hengzhigang Road, Guangzhou 510095, Guangdong, People's Republic of China. ${ }^{2}$ State Key Laboratory of Respiratory Diseases, Guangzhou Institute of Respiratory Disease, Affiliated Cancer Hospital \& Institute of Guangzhou Medical University, Guangzhou, China. ${ }^{3}$ Department of Surgery, Affiliated Cancer Hospital \& Institute of Guangzhou Medical University, No. 78 Hengzhigang Road, Guangzhou 510095, Guangdong, People's Republic of China. ${ }^{4}$ Unit of Hepatobiliary Surgery, Department of General Surgery, Nanfang Hospital, Southern Medical University, 1838 North Guangzhou Avenue, Baiyun District, Guangzhou 510515, China. ${ }^{5}$ Department of Orthopaedics and Traumatology, Nanfang Hospital, Southern Medical University, Guangzhou, China.
\end{abstract}

Received: 28 January 2021 Accepted: 15 March 2021

Published online: 23 March 2021

\section{References}

1. Bray F, Ferlay J, Soerjomataram I, Siegel RL, Torre LA, Jemal A. Global cancer statistics 2018: GLOBOCAN estimates of incidence and mortality worldwide for 36 cancers in 185 countries. CA Cancer J Clin. 2018;68(6):394-424.

2. Chen W, Zheng R, Baade PD, Zhang S, Zeng H, Bray F, Jemal A, Yu XQ, He J. Cancer statistics in China, 2015. CA Cancer J Clin. 2016;66(2):115-32.

3. Coleman MP. Cancer survival: global surveillance will stimulate health policy and improve equity. Lancet. 2014;383(9916):564-73.

4. Reeves HL, Aisen AM. Hepatocellular carcinoma: optimal staging impacts survival. Gastroenterology. 2015;148(7):1274-6.

5. Koh YW, Han JH, Haam S, Jung J, Lee HW. Increased CMTM6 can predict the clinical response to PD-1 inhibitors in non-small cell lung cancer patients. Oncolmmunology. 2019;8(10):e1629261.

6. Chen L, Yang QC, Li YC, Yang LL, Liu JF, Li H, Xiao Y, Bu LL, Zhang WF, Sun ZJ. Targeting CMTM6 suppresses stem cell-like properties and enhances antitumor immunity in head and neck squamous cell carcinoma. Cancer Immunol Res. 2020;8(2):179-91.

7. Guan X, Zhang C, Zhao J, Sun G, Song Q, Jia W. CMTM6 overexpression is associated with molecular and clinical characteristics of malignancy and predicts poor prognosis in gliomas. EBioMedicine. 2018;35:233-43.

8. Mezzadra R, Sun C, Jae LT, Gomez-Eerland R, de Vries E, Wu W, Logtenberg M, Slagter M, Rozeman EA, Hofland I, Broeks A, Horlings HM, Wessels L, Blank CU, Xiao Y, Heck A, Borst J, Brummelkamp TR, Schumacher T. Identification of CMTM6 and CMTM4 as PD-L1 protein regulators. Nature. 2017; 549(7670):106-10

9. Burr ML, Sparbier CE, Chan YC, Williamson JC, Woods K, Beavis PA, Lam E, Henderson MA, Bell CC, Stolzenburg S, Gilan O, Bloor S, Noori T, Morgens DW, Bassik MC, Neeson PJ, Behren A, Darcy PK, Dawson SJ, Voskoboinik I, Trapani JA, Cebon J, Lehner PJ, Dawson MA. CMTM6 maintains the expression of PD-L1 and regulates anti-tumour immunity. Nature. 2017;549(7670):101-5.

10. Yang J, Antin P, Berx G, Blanpain C, Brabletz T, Bronner M, Campbell K, Cano A, Casanova J, Christofori G, Dedhar S, Derynck R, Ford HL, Fuxe J, García DHA, Goodall GJ, Hadjantonakis AK, Huang R, Kalcheim C, Kalluri R, Kang Y, Khew-Goodall Y, Levine H, Liu J, Longmore GD, Mani SA, Massagué J, Mayor R, McClay D, Mostov KE, Newgreen DF, Nieto MA, Puisieux A, Runyan R, Savagner P, Stanger B, Stemmler MP, Takahashi Y, Takeichi M, Theveneau E, Thiery JP, Thompson EW, Weinberg RA, Williams ED, Xing J, Zhou BP, Sheng G. Guidelines and definitions for research on epithelialmesenchymal transition. Nat Rev Mol Cell Biol. 2020;21(6):341-52.

11. Brabletz T, Kalluri R, Nieto MA, Weinberg RA. EMT in cancer. Nat Rev Cancer. 2018;18(2):128-34.

12. Pastushenko I, Blanpain C. EMT transition states during tumor progression and metastasis. Trends Cell Biol. 2019;29(3):212-26.

13. Giannelli G, Koudelkova P, Dituri F, Mikulits W. Role of epithelial to mesenchymal transition in hepatocellular carcinoma. J Hepatol. 2016;65(4):798-808.

14. Jayachandran A, Dhungel B, Steel JC. Epithelial-to-mesenchymal plasticity of cancer stem cells: therapeutic targets in hepatocellular carcinoma. J Hematol Oncol. 2016;9(1):74.

15. Xu Y, Xu H, Li M, Wu H, Guo Y, Chen J, Shan J, Chen X, Shen J, Ma Q, Liu J, Wang M, Zhao W, Hong J, Qi Y, Yao C, Zhang Q, Yang Z, Qian C, Li J. KIAA1199 promotes sorafenib tolerance and the metastasis of hepatocellular carcinoma by activating the EGF/EGFR-dependent epithelial-mesenchymal transition program. Cancer Lett. 2019;454:78-89.

16. Strouhalova K, Přechová M, Gandalovičová A, Brábek J, Gregor M, Rosel D. Vimentin intermediate filaments as potential target for cancer treatment. Cancers. 2020;12(1):184

17. Meng J, Chen S, Han JX, Qian B, Wang XR, Zhong WL, Qin Y, Zhang H, Gao WF, Lei YY, Yang W, Yang L, Zhang C, Liu HJ, Liu YR, Zhou HG, Sun T, Yang C. Twist1 regulates vimentin through Cul2 circular RNA to promote EMT in hepatocellular carcinoma. Can Res. 2018;78(15):4150-62.

18. Zhang H, Wu X, Xiao Y, Wu L, Peng Y, Tang W, Liu G, Sun Y, Wang J, Zhu H, Liu M, Zhang W, Dai W, Jiang P, Li A, Li G, Xiang L, Liu S, Wang J. Coexpression of FOXK1 and vimentin promotes EMT, migration, and invasion in gastric cancer cells. J Mol Med. 2019;97(2):163-76.

19. Zugazagoitia J, Liu Y, Toki M, McGuire J, Ahmed FS, Henick BS, Gupta R, Gettinger SN, Herbst RS, Schalper KA, Rimm DL. Quantitative assessment of CMTM6 in the tumor microenvironment and association with response to PD-1 pathway blockade in advanced-stage non-small cell lung cancer. J Thorac Oncol. 2019;14(12):2084-96.

20. Mittal V. Epithelial mesenchymal transition in tumor metastasis. Annu Rev Pathol. 2018;13:395-412. 
21. Sannino G, Marchetto A, Kirchner T, Grünewald T. Epithelial-to-mesenchymal and mesenchymal-to-epithelial transition in mesenchymal tumors: a paradox in sarcomas? Can Res. 2017;77(17):4556-61.

22. Ngan CY, Yamamoto H, Seshimo I, Tsujino T, Man-i M, Ikeda Jl, Konishi K, Takemasa I, Ikeda M, Sekimoto M, Matsuura N, Monden M. Quantitative evaluation of vimentin expression in tumour stroma of colorectal cancer. Br J Cancer. 2007;96(6):986-92.

23. Andreolas C, Kalogeropoulou M, Voulgari A, Pintzas A. Fra-1 regulates vimentin during Ha-RAS-induced epithelial mesenchymal transition in human colon carcinoma cells. Int J Cancer. 2008;122(8):1745-56.

24. Mei JW, Yang ZY, Xiang HG, Bao R, Ye YY, Ren T, Wang XF, Shu YJ. MicroRNA-1275 inhibits cell migration and invasion in gastric cancer by regulating vimentin and E-cadherin via JAZF1. BMC Cancer. 2019;19(1):740.

25. Chang L, Li C, Lan T, Wu L, Yuan Y, Liu Q, Liu Z. Decreased expression of long non-coding RNA GAS5 indicates a poor prognosis and promotes cell proliferation and invasion in hepatocellular carcinoma by regulating vimentin. Mol Med Rep. 2016;13(2):1541-50.

26. Kidd ME, Shumaker DK, Ridge KM. The role of vimentin intermediate filaments in the progression of lung cancer. Am J Respir Cell Mol Biol. 2014:50(1):1-6.

27. Sharma P, Alsharif S, Fallatah A, Chung BM. Intermediate filaments as effectors of cancer development and metastasis: a focus on keratins, vimentin, and nestin. Cells. 2019;8(5):497.
28. Kim TW, Lee YS, Yun NH, Shin $\mathrm{CH}$, Hong HK, Kim HH, Cho YB. MicroRNA$17-5 p$ regulates EMT by targeting vimentin in colorectal cancer. $\mathrm{Br} J$ Cancer. 2020;123(7):1123-30.

29. Zhu Z, Rong Z, Luo Z, Yu Z, Zhang J, Qiu Z, Huang C. Circular RNA circNHSL1 promotes gastric cancer progression through the miR-1306-3p/ SIX1/vimentin axis. Mol Cancer. 2019;18(1):126.

30. Zeng S, Xie X, Xiao YF, Tang B, Hu CJ, Wang SM, Wu YY, Dong H, Li BS, Yang SM. Long noncoding RNA LINC00675 enhances phosphorylation of vimentin on Ser83 to suppress gastric cancer progression. Cancer Lett. 2018:412:179-87.

31. Chatterjee K, Jana S, DasMahapatra P, Swarnakar S. EGFR-mediated matrix metalloproteinase-7 up-regulation promotes epithelial-mesenchymal transition via ERK1-AP1 axis during ovarian endometriosis progression. Faseb J. 2018;32(8):4560-72.

32. Miyatake Y, Sheehy N, Ikeshita S, Hall WW, Kasahara M. Anchoragedependent multicellular aggregate formation induces CD44 high cancer stem cell-like ATL cells in an NF-kB- and vimentin-dependent manner. Cancer Lett. 2015;357(1):355-63.

\section{Publisher's Note}

Springer Nature remains neutral with regard to jurisdictional claims in published maps and institutional affiliations.
Ready to submit your research? Choose BMC and benefit from:

- fast, convenient online submission

- thorough peer review by experienced researchers in your field

- rapid publication on acceptance

- support for research data, including large and complex data types

- gold Open Access which fosters wider collaboration and increased citations

- maximum visibility for your research: over 100M website views per year

At BMC, research is always in progress.

Learn more biomedcentral.com/submissions 